Celestinesca 32 (2008): 191-207 https://doi.org/10.7203/Celestinesca.32.20114

\title{
Idea de Libertad en La Celestina desde el materialismo filosófico como teoría de la literatura
}

\author{
Jesús G. Maestro \\ Universidad de Vigo
}

PÁrmeno: No querría bienes mal ganados.

Celestina: Yo sí.

La Celestina (Rojas 1499/2000: I, 74).

\section{Idea de Libertad}

En este trabajo voy a analizar, desde los presupuestos metodológicos del materialismo filosófico como teoría literaria contemporánea (Ma tro 2006), la Idea de Libertad que se objetiva en La Celestina de Fernando de Rojas.

La libertad no es cuestión de palabras, sino de hechos y de ideas, es decir, no haré de la libertad una cuestión retórica o ideológica (sofística), sino un concepto científico o categorial (cuyos materiales antropológicos resultarán vinculados a una determinada ciencia categorial: Derecho, Sociología, Ética, Economía...) y una idea filosófica o gnoseológica (idea que resultará de trascender dialécticamente los diferentes campos categoriales sobre los que se construye la praxis de la libertad, los cuales se encuentran relacionados en symplokê). No hablaré, pues, de la libertad en términos retóricos, metafóricos, tropológicos, sino mediante conceptos categoriales e ideas gnoseológicas. Fenomenológicamente se constata que la palabra libertad es hoy en día una palabra completamente adulterada. Tributaria de vindicaciones y prestigios seculares, en nuestro tiempo está irreflexi vamente en boca de todos: filósofos, pensadores, cantantes, políticos, te- 
rroristas, curas, economistas, obreros, emigrantes, dictadores, periodistas $\mathrm{y}$, por supuesto, intelectuales. Su heterogeneidad, acaso inconmensurable, exige higienizarla y delimitarla como Idea para proceder con ella a cualquier aplicación interpretativa posterior. Este proceso de purificación y limpieza de las ideas sólo puede hacerse a través de una filosofía crítica, capaz de recorrer - sin detenerse ante dogmas, prejuicios o intereses gregarios - los diferentes contextos mundanos (ordinarios) y científicos (categoriales) en los que la Libertad ha adquirido un uso consistente, determinante y objetivo. Este recorrido, que el materialismo filosófic denomina regressus, ha de conducirnos a las esencias nucleares de la Idea de Libertad, de modo que, sólo a continuación, estaremos en condiciones de iniciar un progressus que nos permita aplicar esta Idea a un determinado campo categorial de la actividad humana, en nuestro caso, la literatura. Concretamente, La Celestina de Rojas. El regreso (de la materia a la forma) a las esencias y el progreso (de la forma a la materia), desde ellas, hacia los fenómenos del referente material que corresponde a una Idea concreta, en este caso a una Idea de Libertad desarrollada a través de un material literario, constituye uno de los procedimientos operatorios básicos del materialismo filosófico como teoría de la literatura

\section{Fenomenología de La Celestina: tres materializaciones de la Idea de Libertad}

La Idea de Libertad no puede definirse ni interpretarse a partir de un conjunto nulo de premisas. De hecho, el autor de La Celestina sostiene una Idea de Libertad formalmente objetivada en una relación dialéctica compleja (symplokê), rigurosamente determinada y definida por la interacción conflictiva de tres realidades: el Estado, la Ética y la Moral. El Estado es la máxima expresión de una sociedad política, objetivada en un ordenamiento jurídico con competencias y poderes para imponerse de forma efectiva sobre la vida (Ética) de los Individuos y sobre la vida (Moral) de los grupos humanos en connivencia dentro de los límites que comprende el propio Estado. A su vez, la Ética representa esencialmente todo lo relativo a la defensa de la vida del Individuo y de sus intereses más personales. Por su parte, la Moral tiene como finalidad preservar y proteger, por encima de cualesquiera otros fines -incluidos la vida de sus propios miembros, o incluso la eutaxia de un Estado, dentro del cual opera moralmente como gremio- la supervivencia social del grupo o gremio de referencia, es decir, la unidad, organización y destino de una determinada agrupación humana, a cuyos miembros pueden unir lazos sanguíneos (familia), fideístas (religión), ideológicos (partido político), sexistas (feminismos), económicos (multinacionales y grupos empresariales), étnicos y raciales (nacionalismos e indigenismos), físicos (organizaciones de ciegos, 
sordos, mutilados...), medioambientales (grupos ecologistas), zoológicos (asociaciones protectoras de animales), etc. Es indudable que los intereses del Estado, del Individuo y del Gremio, mantienen entre sí relaciones dialécticas y conflictivas, cuya armonización, cuya connivencia incluso, resulta a veces imposible.

Considero aquí al Estado como la máxima expresión ejecutiva de una sociedad política; al Individuo, como el miembro esencial e imprescindible de toda sociedad, sea natural o gentilicia (Gremio), sea política o estatal (Estado), miembro que, como sujeto individual, es sujeto de intereses propios y personales, frente al Gremio y frente al Estado; y al Gremio, como la máxima expresión de la sociedad natural o gentilicia, es decir, de aquella sociedad no política o estatal, y que sin embargo sólo puede existir y desarrollarse dentro de una sociedad política o Estado, dentro de la cual trata de expandirse en beneficio propio, para satisfacción de sus intereses gremiales antes que de los intereses de sus miembros individuales. El objetivo del Estado es la eutaxia, o perfecta organización de todas sus partes para bienestar de todos sus miembros. A este fin, el Estado organiza la vida de sus miembros o individuos políticos tomando como referencia un ordenamiento jurídico, en el que se objetivan y codifican deberes y poderes colectivos, que no necesariamente comunes. A su vez, el Gremio organiza sus intereses bajo la forma de una Moral, en la que se codifican exigencias fundamentales destinadas a la preservación de la unidad y el destino del grupo. Por su parte, el Individuo, determinado por su pertenencia a una sociedad política (Estado) y/o a una sociedad natural o gentilicia (Gremio), al margen de las cuales su supervivencia es imposible, tenderá siempre a servirse de la Ética con objeto de asegurar la satisfacción de sus necesidades y la preservación de sus condiciones de vida, con frecuencia frente al Gremio, y a veces incluso al margen del Estado, incurriendo, si fuera preciso, en el primer caso, en la heterodoxia, y, en el segundo, en la ilegalidad. La dialéctica conflictiva entre Estado, Ética y Moral, es decir, entre Sociedad Política, Individuo y Sociedad Natural o Gentilicia, es determinante en las sociedades civilizadas.

Conviene subrayar aquí que la obra que nos ocupa, La Celestina, no se concibe ni se plantea, en los conflictos que ofrece al lector o espectador, al margen de una sociedad política bien definida, como es el Estado español de fines del siglo xv, ni al margen de unos intereses individuales muy claros, desde el impulso sexual hasta el afán de riqueza más personal, ni tampoco al margen de formas de vida gremiales, propias de sociedades gentilicias como la picaresca y la rufianesca (jábega), la clerecía y el hampa prostibularias, la nobleza degenerada o la emergente burguesía. Todos estos intereses mantienen entre sí relaciones conflictivas y dialécticas, subrayadas desde el comienzo mismo de la digresión que antecede a los autos: 
Todas las cosas ser criadas a manera de contienda o batalla dice aquel gran sabio Heráclito en este modo: «Omnia secundum litem fiunt», sentencia a mi ver digna de perpetua y recordable memoria [...]. Hallé esta sentencia corroborada por aquel gran orador y poeta laureado Francisco Petrarca, diciendo «Sine lite atque offensione nil genuir natura parens", "Sin lid y ofensión ninguna cosa engendró la natura, madre de todo» (Rojas 1499/2000: 15).

El autor otorga a la figura de la dialéctica un valor ontológico fundamental, al considerar que todo cuanto existe es objeto de lucha, enfrentamiento y desenlace bélico, en unos términos que, partiendo del pensamiento heracliteo, sin duda habrían disgustado al teológico y pacifista Erasmo, y sin reservas habrían satisfecho la idea de dialéctica hegeliana con la que comienza la Fenomenología del espíritu (1807). La realidad de la guerra surge sin complejos: "esto con que nos sostenemos, esto con que nos criamos y vivimos, si comienza a ensoberbecerse más de lo acostumbrado, no es sino guerra [...]. Pues entre los animales ningún género carece de guerra» (Rojas, 1499/2000: 16). No pueden minusvalorarse en absoluto estas palabras, que, encabezando la obra, postulan y exigen una interpretación dialéctica de las ideas objetivadas formalmente en sus materiales literarios:

[...] bien afirmaremos ser todas las cosas criadas a manera de contienda [...]. Pues ¿qué diremos entre los hombres a quien todo lo sobredicho es sujeto? ¿Quién explanará sus guerras, sus enemistades, sus envidias, sus aceleramientos y movimientos y descontentamientos? ¿Aquel mudar de trajes, aquel derribar y renovar edificios y otros muchos afectos diversos y variedades que desta nuestra flaca humanidad nos provienen? Y pues es antigua querella y usitada de largos tiempos, no quiero maravillarme si esta presente obra ha seído instrumento de lid o contienda a sus lectores para ponerlos en diferencias, dando a cada uno sentencia sobre ella a sabor de su voluntad [...]; que la mesma vida de los hombres, si bien lo miramos, desde la primera edad hasta que blanquean las canas, es batalla. Los niños con los juegos, los mozos con las letras, los mancebos con los deleites, los viejos con mil especies de enfermedades pelean, y estos papeles con todas las edades (Rojas 1499/2000: 18-20).

Tomando como referencia la dialéctica existente entre los conceptos de Estado, Ética y Moral, es posible interpretar la Idea de Libertad en tres momentos decisivos de la Historia de la Humanidad (Varela 2008), que 
en líneas generales corresponden a lo que denominaremos libertad genitiva, libertad dativa y libertad ablativa (Maestro 2007).

El primer momento corresponde a una Idea primaria de Libertad, propia de sociedades bárbaras, o no civilizadas, es decir, de sociedades humanas organizadas al margen de un Estado, bajo la forma de tribus o filarquías. En este tipo de sociedades la libertad es una lucha abierta por el poder para controlar a los demás, de tal modo que es más libre quien es más fuerte. Así se concibe y desarrolla la libertad en un mundo no civilizado, en un cosmos o biocenosis puramente salvaje o animal, donde la criatura más fuerte es la criatura que dispone de mayor libertad. La libertad de cada uno llega hasta donde llegan sus fuerzas para controlar a los demás. Es lo que denominaremos, más adelante, libertad genitiva. En este contexto, el Derecho del individuo, y por lo tanto también su libertad, equivale a la fuerza de que dispone cada individuo para imponerse a los demás.

El segundo momento de la Idea de Libertad corresponde a la disolución de las sociedades tribales o filarquías y su sustitución por sociedades políticas o estatales, donde la vida social de los seres humanos (no hay sociedades políticas constituidas por animales) se organiza no según la fuerza física de cada cual, sino de acuerdo con un ordenamiento jurídico en el que se objetivan, determinan y legalizan, los límites y las posibilidades que posee cada miembro de la sociedad política o Estado. Ésta es la Idea secundaria de Libertad. Sin embargo, esta segunda materialización de la Idea de Libertad puede desarrollarse en sentido objetivo, si la ejecuta u objetiva el Estado, o en sentido subjetivo, si la ejecuta —o si se la apropia - un determinado Gremio o un determinado Individuo. ¿Por qué? Porque dentro de un Estado o sociedad política siempre hay personas, y grupos de personas, que son capaces de disponer de mayor libertad que otras, bien sirviéndose hábilmente de las leyes, mediante su conocimiento y manipulación (sofística, abogacía y jurisprudencia), bien sustrayéndose a ellas, mediante un incumplimiento más o menos efectivo, arriesgado y punitivo (delincuencia, mafia, terrorismo...). El conflicto que se plantea en La Celestina de Rojas apunta inequívocamente a la dialéctica que se establece entre las ideas de Libertad Objetiva y Libertad Subjetiva, conflicto dialéctico en el que queda comprometido y en entredicho no sólo el ordenamiento jurídico de un Estado, sino las posibilidades de vida de los diferentes gremios e individuos en él implicados. La Idea de Libertad, en su sentido subjetivo, se corresponde con lo que denominaremos libertad dativa, cuya principal fuente causal y volitiva son los Individuos y los Gremios. A su vez, la Idea de Libertad, en su sentido objetivo, se identifica con la denominada libertad ablativa, impuesta y codificada operativamente por un Estado, merced a su sistema policial y militar, es decir, gracias al ejercicio legal y pacificador de la violencia

El tercer momento de la Idea de Libertad corresponde a la que se desarrolla contemporáneamente en la retórica de la llamada posmodernidad. 
Es ésta una idea de libertad que, por complejo ajena a la Edad Moderna, y aún más a la Edad Media, está muy presente, de forma tan acrítica como fraudulenta, en numerosas interpretaciones literarias actuales relativas a cualesquiera épocas históricas. Se trata de una idea retórica de libertad, una imagen psicologista de la libertad cuya materialización es de una fragilidad absoluta, ya que cualquiera puede destruirla, desde el momento en que nada ni nadie la defiende. Ni siquiera con argumentos racionales. Es la idea de libertad ideal, metafísica y armonista, propuesta por sofistas como Rousseau, Habermas o Rawls, entre otros tantos posmodernos. Es una idea de libertad que sólo existe como hecho de conciencia, o como desideratum utópico. Es puro psicologismo. Ningún Estado, ningún Individuo, ningún Gremio, podría organizarse ni preservarse como tal a partir de tal idea de libertad. Evidentemente, es una idea de libertad que no sirve para explicar ni uno solo de cuantos conflictos se dan en La Celestina.

\section{Declinación de la Idea de Libertad: los casos genitivo, dativo y ablativo}

Todos los usos de la Idea de Libertad pueden organizarse o declinarse en tres casos fundamentales, que denominaré genitivo — libertad de - dativo - libertad para- y ablativo - libertad en-. Los tres casos están concatenados entre sí, y se desarrollan de forma integradora, pues siempre que un sujeto existe dispone, o no, es decir, positiva o negativamente, de libertad de hacer algo para algo o alguien en un contexto o circunstancia determinados.

En el primero de estos casos, la libertad genitiva, o libertad de, expresa ante todo la idea de libertad como posesión del sujeto, como atributo del yo, al contener el conjunto de potencias (poder), facultades (saber) y voliciones (querer) que capacitan a un yo para hacer, o no hacer, algo en un contexto determinado. Lo que enfatiza la libertad genitiva son las cualidades del sujeto en tanto que emanan del propio sujeto. La fuerza de la libertad está, en este caso, en las fuerzas materiales de que dispone una persona: sus posibilidades físicas, sus competencias cognoscitivas, sus recursos volitivos. La libertad genitiva representa una concepción positiva de la libertad, en la medida en que, al ejercerla, el sujeto afirma sus posibilidades de ejecutar acciones y operaciones, y también una concepción negativa, en la medida en que no actúe allí donde querría hacerlo y no puede (desajuste entre las modalidades volitiva y potencial), o cuando podría actuar, pero carece de conocimientos suficientes sobre cómo disponer su intervención (desajuste entre las modalidades potencial y cognoscitiva), entre otras combinaciones posibles. En las formas de la vida natural, en la que viven los animales salvajes $-y$ hacia la que irreflexivamente muestran tantas simpatías algunos grupos humanos que propugnan renunciar 
a los modos de la vida civilizada para integrarse en las formas de vida naturales-, al igual que en las sociedades humanas pre-estatales, los límites de la libertad son los límites de la libertad genitiva, es decir, los límites de la fuerza, del conocimiento y del deseo que mueve a las criaturas, tanto humanas como animales. En el mundo animal $-\mathrm{y}$ el ser humano es un animal político, es decir, un ser con capacidad para organizarse políticamente (las hormigas pueden formar una sociedad, pero no una sociedad política) - la libertad del tigre llega hasta donde llega su fuerza, su astucia y su necesidad de depredación. En cautividad, sin embargo, el tigre no caza. No tiene, porque no desarrolla, esa necesidad. Su libertad genitiva es prácticamente inexistente. Del mismo modo, en una sociedad humana no civilizada políticamente, es decir, en una sociedad humana anterior a la constitución del Estado, la libertad genitiva es la que más impera. Los límites de la libertad son los límites de la fuerza personal, los límites de los atributos del yo, incentivados por el deseo y la necesidad, y no condicionados sino por la saciedad del propio yo. La máxima libertad pertenecerá al máximo depredador. He aquí el núcleo de la libertad genitiva, cuyo espacio genuino es el mundo salvaje, previo a la civilización, es decir, al Estado, el cual impondrá sus límites al concepto genitivo de libertad, dando a la colectividad humana, organizada políticamente, una intencionalidad proléptica que habrá de determinar no sólo el sentido y la finalidad de sus acciones, sino también, y muy principalmente, el destino de cada una de ellas. Con el nacimiento del Estado nace también un nuevo concepto de libertad: la libertad dativa. Desde esta perspectiva cabe interpretar la proposición LXXIII de la parte cuarta de la Ética de Spinoza, por ejemplo, donde se advierte que «el hombre que se guía por la razón es más libre en el Estado, donde vive según leyes que obligan a todos, que en la soledad, donde sólo se obedece a sí mismo" (Spinoza, 1677/2004: 365). He aquí el concepto civilizado de libertad, como experiencia sólo posible en la realidad organoléptica de un Estado.

En el segundo caso, la libertad dativa, o libertad para, implica e integra la libertad genitiva, es decir, la acción de un sujeto, determinado por sus potencias, facultades y voliciones, para destinar los contenidos materiales de la acción ejecutada hacia una finalidad proléptica, la cual imprime a la libertad una dimensión teleológica, de cuyo éxito o fracaso dependerán futuras condiciones evolutivas, en las que, como destinatarios, pueden estar implicados tanto sujetos humanos como objetivos operatorios. Lo que enfatizaría la libertad dativa serían ante todo los logros a los que conduce la acción del sujeto libre, de modo que, en este caso, la fuerza de la libertad estaría sobre todo en los contenidos materiales a los que da lugar la acción de un yo que ejerce y ejecuta su libertad genitiva. La libertad dativa puede resultar positiva o negativa, no por la implicación en el curso de las operaciones ejecutadas de las potencias, facultades o voliciones del sujeto, sino sobre todo por relación al grado de prudencia o imprudencia 
que demostrará el resultado teleológico de la acción desarrollada. Un Estado puede disponer positivamente de libertad genitiva, es decir, de potencial, conocimientos y necesidad, y así declarar la guerra a otro Estado con fines diversos (invasión, control de sus fuentes de energía, prevención de ataques de Estados vecinos, etc.), pero algo así no asegura que su libertad dativa resulte igualmente positiva. No lo será si pierde la guerra. Es decir, si la teleología de los hechos revela que la acción bélica ha sido una imprudencia. En ese contexto, la libertad dativa del Estado que declara la guerra será una libertad dativamente negativa. Algo ha cercenado sus pretensiones de libertad. Una experiencia ablativa.

El tercer caso es el de la libertad ablativa, o libertad en, la cual implica e integra las dos anteriores, esto es, la libertad genitiva de un sujeto y la libertad dativa de las consecuencias de su acción, que, en términos de libertad ablativa, resulta contextualizada o circunstancializada en una codeterminación de fuerzas, las cuales actúan materialmente sancionando y clausurando el estado de la acción ejecutada. La libertad ablativa, o libertad en, representa siempre una concepción negativa de la libertad, porque en todo contexto en el que se manifieste la libertad, ésta habrá de enfrentarse a fuerzas negativas, resistencias ante sujetos, objetos o situaciones. La libertad ablativa representa el espacio de la confrontación, los límites de la libertad genitiva - los límites de la fuerza, de la necesidad, del entusiasmo, del saber-y la comprobación de las consecuencias de la libertad dativa - los resultados de éxito o fracaso a los que ha conducido la prudencia o imprudencia de una acción-, el grado de inmunidad frente a la resistencia que hay que superar, es decir, el precio del ejercicio de la libertad, el coste de la acción, la hipoteca de los hechos. En una palabra: el número y el coste de las bajas. La libertad ablativa es, en suma, una expresión acaso oximorónica, que remite sin duda a los cércenos que ha de padecer el sujeto libre. Hablar de libertad ablativa es en cierto modo hablar de ablación de la libertad. La libertad equivale en estos casos, dada la codeterminación de fuerzas que actúan y operan en el contexto, a la afirmación de determinaciones exteriores, a la implantación de imposiciones exteriores que coaccionan al sujeto que pretende ejercer su libertad, limitando sus atributos genitivos y sus consecuencias dativas. La libertad ablativa supone el cierre, el corte, el cercén, de las libertades genitiva y dativa. En las sociedades bárbaras, una codeterminación de fuerzas distintas y adversas entre sí materializa la acción cercenadora o erosiva de la libertad ablativa. En las sociedades civilizadas, el Estado se constituye en la principal institución ablativa de la libertad. In extremis, ésta es la tesis del anarquismo. En una sociedad política la libertad se limita, se regula, se cercena, con el fin de evitar la depredación y de este modo hacer posible la convivencia. Esta convivencia no es pacífica en ninguna sociedad, pues las leyes castigan con mayor o menor violencia - también en tiempos llamados de paz- aquellos intentos de depreda- 
ción que, conforme a un ordenamiento jurídico, los tribunales de justicia identifican y sancionan como tales. De cualquier modo, los criterios para regular la Idea de Libertad siguen siendo a diario objeto de disputa respecto a toda sociedad política.

En suma, libertad genitiva es la libertad de que dispone el yo a la hora de actuar y de ejecutar determinadas acciones. Libertad dativa sería la que ese mismo yo desarrolla para conseguir determinados logros materiales. Por último, libertad ablativa será aquella que limita la libertad genitiva y la libertad dativa de ese yo, es decir, la libertad que contrarresta las acciones (desde el punto de vista de su grado de posibilidad, conocimiento y volición) y los objetivos de ese yo. La libertad ablativa no es solamente la libertad de los demás tratando de actuar sobre la mía ${ }^{1}$, lo que nos sitúa en el eje circular (humano, personal, social) del espacio antropológico, sino también el contexto en el que yo actúo, con toda la codeterminación de fuerzas que operan en él, erosionando mi capacidad y mis posibilidades de acción, es decir, desde los referentes que se objetivan en el eje radial del espacio antropológico (la Naturaleza y sus fuerzas físicas, las cuales sin duda ofrecen mayor o menor resistencia a las acciones de un sujeto operatorio humano).

Sólo cuando se proyecta una acción (libertad dativa) de la que el sujeto se siente capaz (libertad genitiva) se podrá advertir con precisión las trabas que impiden ejercerla (libertada ablativa). Incluso cabe hablar de tales obstáculos, es decir, de la ablación de la libertad, como de un despliegue de dificultades objetivas que se objetivan precisamente por el hecho mismo de ejercer la libertad (genitiva) con fines prolépticos o intencionales (dativa). Es, pues, evidente, que la libertad ablativa se manifiesta en el proceso de vencer o dominar las trabas y dificultades inherentes a todo ejercicio de libertad, el cual, al brotar del sujeto y pretender fines objetivos, califico respectivamente de genitivo y de dativo. Si la libertad (genitiva) de un individuo nos impide hacer lo que las leyes nos permiten (es decir, amenaza nuestra propia libertad genitiva), podremos resistirla contando con la ayuda del Estado, el cual en este caso ejercerá para nosotros una libertad dativa, y para el individuo que nos oprime una libertad ablativa. En consecuencia, en las sociedades civilizadas no cabe hablar propiamente de Libertad al margen del Estado. Es obvio que el Estado libera (dativamente) al ser humano de las amenazas que serían propias en el "estado de la Naturaleza», y que de forma simultánea le impone (ablativamente) unos límites que recortan y organizan sus formas de conducta, de tal forma que el resultado es un sistema de deberes y derechos objetivados en un ordenamiento jurídico. Todo lo cual supone una Razón

1.- Es el sentido que trataría de expresar el tópico de que «la libertad de cada uno termina donde empieza la libertad del otro». Frase que así expresada resulta de una ambigüedad esterilizante, porque lo que de veras resulta importante y decisivo es saber precisamente en qué punto termina "mi libertad» y hasta qué punto se extiende «la tuya». 
social y política de ser, es decir, una educación, un Estado y un gobierno libremente elegido, es decir, una Democracia, fuera de la cual no cabe, en rigor, hablar de libertad política.

\section{La Celestina y la libertad secundaria subjetiva o libertad dativa}

¿Hay lugar en La Celestina para el azar o indeterminismo? La respuesta es que no. Porque nadie actúa azarosa o indeterminadamente. Nadie actúa sin causas, es decir, nadie opera al azar. No es posible obrar desde el acausalismo, desde el momento en que nadie vive, ni puede vivir, en un mundo sin causas. Sin embargo, sí es posible obrar, e incluso también vivir, en la impotencia, esto es, en la supresión de toda libertad. Como trataré de demostrar, precisamente en la impotencia desembocan determinados personajes de La Celestina, como Melibea, cuyo suicidio no es sino la autosupresión de la vida, es decir, la destrucción de toda potencia personal, ante la imposibilidad de seguir viviendo en un mundo donde, para una mujer como ella, la única causa es la nada. Melibea se suicida cuando constata que su libertad dativa es igual a cero. No ha conseguido nada. La vida no le resulta rentable. Ni factible.

La Libertad por la que luchan los personajes de La Celestina no es la libertad del ácrata (libertad genitiva o primaria), pues luchan en un mundo estatalizado, desde el momento en que viven en el seno de una sociedad política (libertad ablativa o secundaria objetiva), reglada y fundamentada en un ordenamiento jurídico objetivo. Sin embargo, su lucha por satisfacerse en el disfrute de ciertas libertades (libertades dativas o secundarias subjetivas) discurre al margen de la Ley, e incluso pretende instituir una "justicia» gremial, gregaria, subjetiva, dativa, propia del grupo que, cual gremio de rufianes, prostitutas y clientes, en clara dialéctica con la Justicia que instituye, y en que se objetiva, el ordenamiento jurídico de un Estado. Pármeno y Sempronio se creen con "derecho" a disponer de las "riquezas" de Celestina en sus «negocios» con Calisto. Areúsa y Elicia se consideran autorizadas a «ajusticiar» a Calisto, y a Melibea, contratando a Centurio para ajustar las cuentas con una clase social que dispone de ventajas económicas y laborales frente a la forma de vida que llevaban Celestina, Pármeno, Sempronio, o las propias discípulas de la madre prostibularia. Desde este punto de vista, una obra como La Celestina plantea un conflicto dialéctico entre la Ética del individuo, como ser humano (que lucha por su bienestar personal: libertad genitiva o primaria), la Moral del gremio, como sociedad natural o gentilicia (que lucha por la preservación de sus privilegios frente a otros grupos, incluido el Estado, y frente a otros individuos, incluidos los miembros individuales del Estado: libertad dativa o secundaria subjetiva), y el Derecho del propio Estado, como sociedad polí- 
tica (que lucha por hacer cumplir una Ley objetivada en un ordenamiento jurídico cuya operatividad está garantiza por un sistema policial y militar: libertad ablativa o secundaria objetiva).

El concepto de Libertad que mueve a los personajes de La Celestina no es un concepto anarquista, ni acausalista, es decir, no se basa en el ejercicio ilimitado de la libertad genitiva del individuo frente a la imposición controlada de la libertad ablativa del Estado. No es la libertad del hombre salvaje, la libertad del bárbaro frente a la civilización, la libertad que desea el individuo depredador frente al Estado generador. No. Es la libertad determinada por los impulsos del individuo que opera, frente al Estado, desde la iniciativa del grupo social. Es la libertad dativa, individual o gremial, que, en su lucha por satisfacerse, tropieza con la libertad ablativa y objetiva del Estado. Es, en suma, la libertad de unos rufianes cuyo desenvolvimiento y materialización conduce al fracaso a cuantos se sienten seducidos a participar en su ejercicio. El desenlace de la obra condena, desde el estatalismo, desde una justicia secular, a los personajes que han ejercitado una libertad contraria a las normas de una sociedad política definida. Y es el mismo desenlace de la obra el que impide una solución metafísica y trascendente de los hechos. Se impone una solución política y materialista. La religión se descarta y anula. Ningún dios heredará las consecuencias de los actos de los personajes. Ningún dios escucha las últimas voluntades de Melibea ni las imprecaciones del monólogo de Pleberio. Las palabras de este último son una rogativa destinada a la nada. Un discurso en el que se codifica un mundo nihilista. Ni siquiera los seres humanos prestarán atención a las últimas voluntades de una suicida como Melibea, que pretende ser enterrada junto al cadáver de alguien tan antiheroico como Calisto. Se impone una solución nihilista a un desenlace estatalista. Ni siquiera la Religión se presenta en La Celestina como una Ley que esté por encima del Estado, como décadas más tarde sucederá en la mayoría de las obras literarias del Siglo de Oro, y como de forma especialmente singular sucede en el Quijote, donde la Religión es ante todo, y de forma exclusiva, una Ley institucional, y no un sentimiento, frente a lo que, entonces contemporáneamente, propugnaba el erasmismo y el protestantismo. ¿¿Por qué? Porque en La Celestina la Religión no es un estado anímico, ni una demostración de fe, ni una experiencia interior, ni una cuestión personal, como pretenderían inmediatamente Lutero y Erasmo, frente a la articulación institucional, estatal y política, que insistía en conferirle el catolicismo, y que de hecho le confirmó Trento. En La Celestina la Religión es un código muy ajeno a la intimidad de los personajes, del que éstos se sirven, y en el que participan, en la medida en que se integran en un orden social del que disienten, y dentro del cual se comportan como hipócritas, cínicos y embaucadores. No por casualidad Sempronio advertirá tempranamente a Calisto con estas acusativas palabras: 
Sempronio.- Porque lo que dices contradice la cristiana religión.

CALISTO.- ¿Qué a mí?

Sempronio.- ¿Tú no eres cristiano?

Calisto.- ¿Yo? Melibeo só y a Melibea adoro y en Melibea creo y a Melibea amo (Rojas 1499/2000: I, 34)2.

El propio autor (o autores) de La Celestina no revela en la composición de la obra ninguna afinidad hacia ningún código religioso específico, ni hebreo, ni cristiano, ni musulmán ${ }^{3}$. La Religión, como sentimiento, es un ejercicio de hipocresía, de cinismo y de parodia, al fingir e invocar unas creencias que se adulteran eficazmente en el curso de la vida práctica; y como institución, la Religión actúa como un orden social que existe sólo cultural y oficialmente en la medida en que se incumple biológica y realmente, al asumir formas de conducta que se sustraen a los fundamentos y exigencias de esa ordenación, entre las cuales la más destacada es la de frecuentar prostíbulos y tratar con alcahuetas ${ }^{4}$.

Sucede en La Celestina que la libertad dativa (o secundaria subjetiva) obedece, en primer lugar, al proyecto de un sujeto frente a, o en contra de, otros sujetos. Ejercer la libertad, en cualquier de sus casos, declinaciones y materializaciones, es ejercerla contra alguien. No hay libertad sin dialéctica, del mismo modo que no hay libertad sin causas ni determinismos. Sólo desde la impotencia, cuya consecuencia es el nihilismo, y cuyas causas - que siempre habrá que explicar- pueden ser varias, cabe hablar de negación o inexistencia de libertad 5 .

En segundo lugar, la libertad dativa requiere por parte del individuo que pretende ejercerla un plan racional, es decir, una ordenación teleológica

2.- So capa de tópico literario medieval, codificado en las trovas provenzales, pasó impune esta declaración hasta caer en los ojos de los censores inquisitoriales de 1640, quienes sí se tomaron en serio la licencia poética tardomedieval.

3.- Irónicamente se advierte que lo único que tienen en común los diferentes credos religiosos, e incluso los ateos, como grupo religioso negativamente considerado, es en estar seguros y de acuerdo en que Celestina es bruja y alcahueta, entre otros menesteres: "Gentiles, judíos, cristianos y moros; todos en esta concordia están» (Rojas 1499/2000: I, 39). Lo mismo cabe decir de las visitas de Calisto a la iglesia a fin de oír misa, y rogar a dios porque Celestina, "cliéntula» del diablo, logre con embustes el «amor» de Melibea: "Agora lo creo, que tañen a misa. Daca mis ropas. Iré a la Madalena; rogaré a Dios aderece a Celestina y ponga en corazón a Melibea de mi remedio» (Rojas 1499/2000: 196).

4.- La parodia del código religioso es manifiesta en lugares puntuales de La Celestina. Así ocurre cuando Calisto despide a Sempronio, que sale a contratar los servicios de la alcahueta: «Y contigo vaya. ¡Oh todopoderoso, perdurable Dios, tú que guías los perdidos y los reyes orientales por el estrella precedente a Betlén trujiste trujiste y en su patria los redujiste, humildemente te ruego que guíes a mi Sempronio, en manera que convierta mi pena y tristeza en gozo, y yo, indigno, merezca venir en el deseado fin!» (Rojas 1499/2000: I, 48).

5.- En relación con la idea de libertad, no puede soslayarse la importancia que adquiere el personaje nihilista, alguien que por su condición y naturaleza no puede ser ni sincero ni inocente (Maestro 2001). 
de los hechos, indudablemente prevista y potencial. No hay libertad dativa sin intención proléptica definida subjetivamente. La libertad dativa requiere del sujeto la puesta en juego de sus capacidades racionales, en la medida en que exige y supone un plan con una determinada finalidad, y unos planteamientos que tengan en cuenta las variables y obstáculos sobre los que habrán de organizarse la acciones del propio sujeto. Se trata, en suma, de una libertad teleológica, proléptica, potencial, esencialmente operatoria, es decir, una libertad que merecerá el nombre de tal en la medida en que consiga los objetivos propuestos, y en la medida en que tales logros y objetivos permitan actuar, o haber actuado, libremente, controlando y dominando los actos de los demás.

Es importante advertir en este punto que uno de los personajes que menos planifica su ejercicio de libertad es Pármeno, llevado de un lado a otro, entre Celestina, Sempronio y Calisto, por los caminos que parten de sus resistencia a enriquecerse ilegítimamente hasta desembocar en la cama de Areúsa y en la deriva ambiciosa y criminal que le induce fina mente a asesinar a la alcahueta. El parlamento con el que Pármeno concluye el auto segundo, despechado por su amo Calisto, es fundamental para explicar y justificar su modo de actuar. La dialéctica entre el amo y el siervo resulta aquí especialmente luminosa desde el punto de vista del desarrollo ulterior de la acción:

¡Oh desdichado de mí! Por ser leal padezco mal. Otros se ganan por malos, yo me pierdo por bueno. El mundo es tal; quiero irme al hilo de la gente, pues a los traidores llaman discretos; a los fieles, necios. Si yo creyera a Celestina con sus seis docenas de años a cuestas, no me maltratara Calisto. Mas esto me porná escarmiento de aquí adelante con él, que si dijere "Comamos», yo también; si quisiere derrocar la casas, aprobarlo; si quemar su hacienda, ir por huego. Destruya, rompa, quiebre, dañe; dé a alcahuetas lo suyo, que mi parte me cabrá. Pues dice "A río revuelto, ganancia de pescadores». ¡Nunca más perro a molino! (Rojas 1499/2000: II, 92-93).

Muestra este parlamento cómo el criado no se corrompe exactamente por causa de Celestina, sino de Calisto, dada la impotencia de su amo para razonar y para comprender la verdad de los hechos. Pármeno se percata de que no hay solución racional para advertir a Calisto de los errores que está cometiendo. Si los hechos no tienen solución, mejor no perder el tiempo tratando de resolverlos. Pármeno renuncia a ejercer su libertad para ayudar a Calisto, y en su lugar se dispone a seguir los planes de Celestina y de Sempronio. Es decir, asume una teleología ajena, una prolepsis que nunca controlará, dado que no se incorpora a ella como artífice, sino como consecuencia, por lo demás, tardía. La razón — piensa 
Pármeno- no sirve, porque el mundo —el mundo de su amo, «mundo» al cual el siervo está sometido- la rechaza. En adelante, Pármeno actuará conforme a este postulado, pero sin iniciativa propia. No combatirá los prejuicios, sino que se aprovechará de ellos, pero siguiendo dictados ajenos, de la mano de Celestina y de Sempronio, no de su propia razón 6 .

En tercer lugar, la libertad dativa depende siempre de lo que el individuo operatorio que la ejerce consiga como consecuencia de la ejecución de tales ejercicios y operaciones. Es una libertad operatoria. En este sentido, los logros de la libertad dativa que ejerce un individuo son siempre logros adquiridos como consecuencia de la ablación de la libertad dativa de otros individuos, que disputan por logros afines o comunes. Quien pierde la vida por conseguir un logro determinado adquiere, por supuesto negativamente, una libertad dativa que es igual a cero, desde el momento en que se sitúa en el grado máximo de impotencia: la imposibilidad de vivir. Este desenlace determina la libertad de casi todos los personajes de La Celestina. El asesinato de la protagonista a manos de sus supuestos colaboradores o cómplices, el ajusticiamiento, casi popular, de Pármeno y Sempronio, la muerte accidental y decisiva de Calisto, completamente antiheroica, y el suicidio racional, con ribetes de estoicismo, de la propia Melibea, son un despliegue de situaciones letales que sitúan a cada uno de los personajes en una posición de impotencia absoluta y de completa nulidad en cuanto a los logros y pretensiones derivados de su ejercicio de libertad. Lo único que consiguen es verse abocados a la muerte. Sólo se encuentran con razones que los excluyen políticamente del mundo de los vivos, esto es, se ven enfrentados a un Logos que los expulsa de la sociedad política dentro de la cual se les permitió actuar, ejerciendo una libertad meramente genitiva o primaria. El ejercicio de su libertad dativa les ha conducido a perecer a través de un repertorio de formas nada casuales: Celestina, a manos de rufianes, de forma ilegal; Pármeno y Sempronio, como delincuentes, mueren ejecutados ante la Ley y la Justicia, conforme a Derecho; Calisto, en su ociosidad clandestina, fallece calamitosamente como consecuencia accidental de su torpeza y la de los suyos; Melibea, privada de honor público y social, y arropada en la dignidad de una suerte de stoa tan personal como subjetiva, opta por el suicidio, confiando a una voluntariosa muerte sus últimas potencias vitales. Se trata, pues, como he indicado, de una libertad operatoria, que naturalmente requiere las operaciones de un sujeto y que se da siempre materializada y exteriorizada en las acciones de ese sujeto operatorio.

En cuarto lugar, ha de advertirse que la libertad dativa es una libertad muy condicionada, desde el momento en que el sujeto operatorio ha de

6.- No muy distinta será la conducta de Sempronio, quien no tardará en someterse por entero a Celestina, al declararle «haz a tu voluntad, que no será éste el primero negocio que has tomado a cargo» (Rojas 1499/2000: III, 98). 
tener en cuenta numerosos factores, condiciones y circunstancias para llevar a cabo su acción. Y es precisamente la combinación de estos factores, condiciones y circunstancias la que, en relación dialéctica con las operaciones del propio sujeto, ejerce una función ablativa respecto a sus formas de conducta y posibilidades dativas. Tales factores abarcan desde sus propias capacidades individuales hasta las múltiples barreras sociopolíticas con que habrá de contar para hacer que triunfen sus intereses personales. La libertad (dativa) de Celestina tropieza, y perece, ante la libertad (genitiva) de Pármeno y Sempronio, que, más fuertes físicamente que ella, la matan ante la impotencia de Elicia, que carece de libertad de acción para evitar el crimen. Lo único que Elicia puede hacer es gritar e invocar a la justicia política para que prenda a los asesinos, y los ejecute. Pero no ha podido evitar el crimen. A su vez, la libertad (dativa) de Calisto se orienta a lograr el cuerpo de Melibea, sirviéndose de su dinero como único medio y poder (libertad genitiva) superando inicialmente los obstáculos que se plantean (libertad ablativa), y que sin embargo acabarán poco después por hacerle perecer ${ }^{7}$. Elicia y Areúsa dispondrán que los hechos provoquen en Calisto un accidente mortal, aunque no exactamente de la forma en que ellas los habían previsto. La libertad (dativa) de Melibea, orientada a la consecución del gozo de Calisto, se ve cercenada por la muerte lamentable y pública de su amante, así como por el descubrimiento ignominioso de unas relaciones secretas y prohibidas. Melibea no ha conseguido nada en el ejercicio de su libertad (dativa). Su única salida es la supresión de sí misma, no sólo como ser humano político (privación de vida pública, posible reclusión en un convento, etc.), sino como ser humano físico (privación voluntaria y consciente de vida biológica: suicidio).

En quinto lugar, como se habrá observado, la libertad dativa, o secundaria en sentido subjetivo, se desenvuelve dialécticamente en los ámbitos de la Ética (preservación o no de la vida del individuo) y de la Moral (supervivencia o extinción del gremio), y siempre frente al dominio de la Moral objetivada en el Estado, esto es, del Derecho, siendo el Estado, como en efecto lo es, el gremio más poderoso, desde el punto de vista político, jurídico y militar o policial. Por esta razón, el Estado siempre está en condiciones, en circunstancias, de ejercer la libertad ablativa, es decir, la ablación de la libertad de los grupos (moral gremial) y de los individuos (ética personal) que actúan en su seno, dentro de su sociedad política.

En conclusión, la existencia o no de Libertad dependerá esencialmente - casi podríamos decir dativamente - del resultado final del proceso. Hablar de la existencia de libertad dativa, de libertad en términos subjetivos,

7.- Calisto, Celestina y Pleberio tienen en común suponer que «todo lo puede el dinero» (Rojas 1499/2000: III, 102). Naturalmente, fracasan, ya que el dinero, medida de todas las cosas, no es ajeno a la dialéctica que determina su pérdida o su ganancia, por supuesto, mediante la lucha por el poder para controlar a los demás. 
previamente a la finalización del plan de actuación será incurrir en idealismo, en pura metafísica. Es una absoluta petición de principio, porque la libertad no se da al margen de causas, determinaciones y consecuencias, es decir, no se da sin circunstancias cercenadoras, esto es, sin ablaciones. El Estado objetiva la libertad dativa de gremios y de individuos ajustándola a un ordenamiento jurídico, salvaguardado por la violencia de la guerra, mediante el ejército, frente a otros Estados, y por la imposición de la paz, mediante un sistema policial, frente a gremios e individuos que pretendan desacatarlo. 


\section{Bibliografía citada}

Bueno, Gustavo, Ensayos materialistas, Madrid, Taurus, 1972.

-, Materia, Oviedo, Pentalfa, 1990.

- Teoría del cierre categorial, Oviedo, Pentalfa, 1992, 5 vols.

Maestro, Jesús G., El personaje nihilista. 'La Celestina' y el teatro europeo, Frankfurt \& Madrid, Iberoamericana \& Vervuert, 2001.

- La Academia contra Babel. Postulados fundamentales del materialismo filosófico como teoría literaria contemporánea, Pontevedra, Mirabel Editorial, 2006.

- El concepto de ficción en la literatura. (Desde el Materialismo Filosófico como teoría literaria contemporánea), Pontevedra, Mirabel Editorial, 2006.

- Las ascuas del Imperio. Crítica de las Novelas ejemplares de Cervantes desde el materialismo filosófico, Vigo, Editorial Academia del Hispanismo, 2007.

- Los venenos de la literatura. Idea y Concepto de la Literatura desde el Materialismo Filosófico, Vigo, Editorial Academia del Hispanismo, 2007.

- Los materiales literarios. La reconstrucción de la Literatura tras la esterilidad de la "teoría literaria» posmoderna, Vigo, Editorial Academia del Hispanismo, 2007.

- Idea, concepto y método de la Literatura Comparada. Desde el Materialismo Filosófico como Teoría de la Literatura, Vigo, Editorial Academia del Hispanismo, 2008.

RojAs, Fernando de (y «antiguo autor»), La Celestina. Tragicomedia de Calisto y Melibea, Barcelona, Crítica [1499]. Edición y estudio de Francisco J. Lobera, Guillermo Serés, Paloma Días-Mas, Carlos Mota, Íñigo Arzálluz y Francisco Rico, 2000.

SpINozA, Baruch, Ética, Madrid, Alianza Editorial [1677]. Introducción, traducción y notas de Vidal Peña, 2004.

Varela Álvarez, Violeta, Destino y libertad en la tragedia griega, Vigo, Editorial Academia del Hispanismo, 2008. 
Maestro, Jesús G., «Idea de libertad en La Celestina desde el materialismo filosófico como teoría de la literatura", Celestinesca, 32 (2008), pp. 191-207.

\section{RESUMEN}

Este trabajo ofrece un análisis de la idea de libertad en La Celestina desde el Materialismo filosófic como Teoría de la literatura. Se concibe la libertad como la lucha por el poder para controlar a los demás.

Palabras ClaVe: Materialismo filosófico, eoría de la literatura, Libertad, Poder.

\section{ABSTRACT}

This essay offers an analysis of the idea of freedom in La Celestina from the Philosophical Materialism as a Theory of Literature. The freedom is conceived as the fight by the power to control to the other .

KEY WORDS: Philosophical Materialism, Theory of Literature, Freedom, Power.

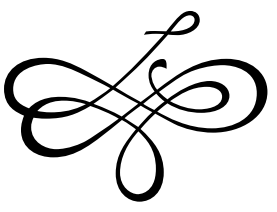

